\title{
APPLICATION OF WECHAT PLATFORM IN SINO-FOREIGN COOPERATIVE UNDERGRADUATE EDUCATION COURSES
}

\author{
Jiguang Guo and Zhiqiang Luan \\ International College Beijing \\ China Agricultural University, Beijing, 100083, P.R. China
}

\begin{abstract}
The research is to use the factor analysis method and statistical classification, finding out the problems existing in the current WeChat public account. The functions should be promoted in order to provide more professional services. For instance, the result illustrates that students of Sino-foreign cooperative education are more interested in personal development and job recruitment information, so WeChat should add and optimize internship or job recommendation function. In addition, making a step-by-step refinement of the research object and content, and finally give reasonable suggestions for the application of WeChat platform in the professional courses of Sino-foreign cooperative undergraduate students through data analysis.
\end{abstract}

\section{KEYWORDS}

WeChat Platform Application, Higher Education Research, Sino-Foreign Cooperative Education, Professional Courses

\section{INTRODUCTION}

With the development of WeChat function, increasingly people apply it to work or study. In China, WeChat is one of the most popular instant messaging applications. It has five main education advantages: versatility, personalization, accessibility, interactivity, and affordability (Shi, Luo \& He, 2017). Nowadays, many universities in China have their own WeChat platform which is always used in daily teaching and learning practice by a lot of teachers and students. For example, teachers are able to send classroom assignments and tests to students through the school WeChat platform. Similarly, students can also use it for practicing course exercises and group discussions, and even submit assignments directly through the platform. Moreover, they might be able to learn online courses and review knowledge whenever they want, which are so convenient for studying. For teachers, they can save much time in printing assignments and judgment. The system even can identify right or wrong answers automatically.

In general, the WeChat platform provides great convenience for both teacher and student learning. This paper narrows the scope of research from the general school WeChat public platform research to focus on the application of WeChat platform in undergraduate professional courses. In addition, with the popularity of Sino-foreign cooperative education projects in recent years, the research population has been further reduced to students of Sino-foreign cooperative education projects.

\section{LITERATURE REVIEW}

\subsection{New Media Era Micro-Learning}

Dr. Desmond Kie, an international distance education technology expert from Ireland, pointed out that M-Learning will be the main way of continuing education in the future. In the process of mobile learning, the "micro" characteristics of learning resources, learning time, learning medium and other elements are obvious. 
Therefore, Austrian study and research expert Lindner proposed the concept of micro-learning, which is expressed as a kind of pointing in the new media ecosystem. A new form of learning based on micro-content and micro-media. Mobile learning can be seen as the main form of micro-learning in the new media age (Zhang $\& \mathrm{Wu}, 2013)$.

\subsection{China Mobile Internet Development Trend}

Owing to the steady development of China's economy and technology, the development trend of China's mobile Internet shows constant progress and structural optimization. It can be seen from the Mobile Internet Blue Book "China Mobile Internet Development Report (2018)", Mobile Internet user growth has slowed down. Moreover, user structure has been improved, and data traffic has doubled, which built the world's largest mobile Internet application market (Yu \& Tang, 2019).

\subsection{Refer to China Statistical Report on Internet Development}

As the degree of online education mobility deepens, WeChat becomes an important tool for mobile learning. The rapid spread of smart devices and other developments. For example, the Internet has created more opportunities for education. Lightweight, fragmented, and structured knowledge is more suitable for mobile learning scenarios. According to the China Statistical Report on Internet Development (2019), as of December 2018 , users who contacted online education through mobile phones accounted for $96.5 \%$ of the total online education users. There is an increase of 19.9 percentage points from the end of 2017. Due to the advantages of WeChat in terms of traffic acquisition, community operation, user scale and stickiness, more and more educational products are beginning to use WeChat to explore new service models. They attract users to learn online through WeChat group, public number, small program and other tools, which continue to share to reduce the cost of acquiring new users and increase user stickiness (China Internet Network Information Center, 2019).

\section{RESEARCH METHODS}

\subsection{Quantitative Research and Data Analysis}

The researchers use the questionnaire to conduct quantitative analysis of college students. The purpose is to gain a deeper understanding of the specific events that current college students are concerned about, which mainly because the college students' wishes and feedback are of great significance to this research. Next, using factor analysis to illustrate the correlation between the various elements. Finally, getting the most needed results for college students.

\subsection{Online Questionnaire}

Data is collected by issuing online questionnaires among college students. Before starting the survey, 50 questionnaires were sent to the study to ensure the reliability and validity of the questionnaire questions. After further adjusting and optimizing the questionnaire questions, 362 questionnaires were finally collected. The data reliability and validity of the study are high and can be used for further analysis (Table 1, Table 2, Table 3).

\subsection{Modelling}

Factor analysis, using a few factors to describe the relationship between many indicators and factors. The way is to classify several closely related variables into the same class. Each type of variable becomes a factor, reflecting the original data with a few factors. Using this research technique, we can easily identify the main factors that influence consumer purchases, consumption, and satisfaction, as well as their impact. Starting from the related dependencies within the research variables, some variables with intricate relationships are attributed to a multivariate statistical analysis method with a few comprehensive factors (Kim \& Mueller, 1978). 


\section{QUANTITATIVE RESEARCH}

Cronbach's Alpha $(0.758)>0.7$, so questionnaire reliability is better (Table 1$)$.

Table 1. Reliability statistics

\begin{tabular}{cc}
\hline Cronbach's Alpha & Number of items \\
\hline .758 & 20 \\
\hline
\end{tabular}

The questionnaire was distributed 362, and all the data of 362 questionnaires were finally used (Table 2).

Table 2. Case processing summary

\begin{tabular}{cccc}
\hline & Heading level & $\mathrm{N}$ & $\%$ \\
\hline \multirow{3}{*}{ Case } & First level heading & 362 & 100.0 \\
& Second level heading & 0 & .0 \\
& Third level heading & 362 & 100.0 \\
\hline
\end{tabular}

a. Deleted in this program based on a list of all variables.

To ensure more accurate results, the researchers extracted the questionnaire data. The final KMO is $0.854>0.5$, indicating that there is a correlation between the variables and meets the requirements. Also sig. $<0.05$, so this data can be factored (Table 3).

Table 3. KMO and Bartlett's inspection

\begin{tabular}{ccc}
\hline \multicolumn{2}{c}{ Sampling enough Kaiser-Meyer-Olkin metrics. } & .854 \\
\hline & Approximate chi square & 2323.962 \\
Bartlett's sphericity test & df & 190 \\
& Sig. & .000 \\
\hline
\end{tabular}

\section{DATA ANALYSIS}

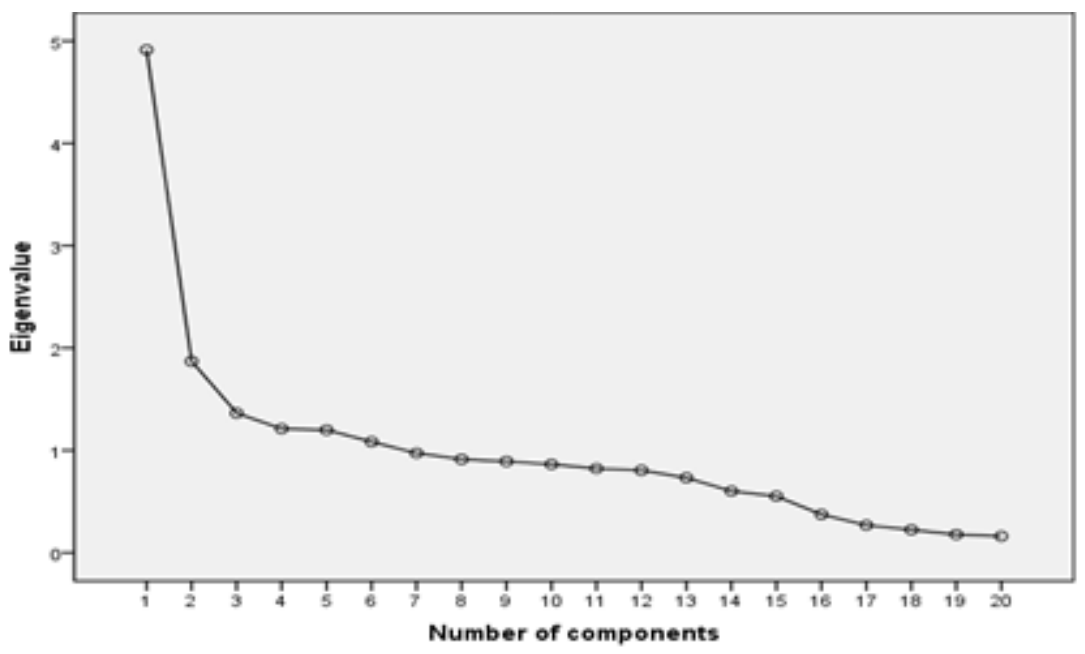

Figure 1. Scree plot

Taking the point with a larger slope is the main factor of this factor. It is mainly combined with the cumulative contribution rate to obtain several factors as the main factors, which is to achieve the dimensionality reduction (Figure 1). 
Table 4. Common factor variance

\begin{tabular}{lcr}
\hline \multicolumn{1}{c}{ Questions } & initial & extract \\
\hline Q1 Your profession? & 1.000 & .483 \\
Q2 What is your current type of schooling? & 1.000 & .319 \\
Q3 Your current grade & 1.000 & .605 \\
Q4 Which of the following do you think is most important to you (based on the WeChat platform)? & 1.000 & .452 \\
Q5What do you think is the most important thing you need to improve in your studies? & 1.000 & .464 \\
Q6 Which of the following functions do you think the current WeChat public account should add? & 1.000 & .559 \\
(emergency) & \\
Q7 College continues to maintain the original network platform is not improved, are you willing to & 1.000 & .574 \\
use the college public number all the time? & 1.000 & .355 \\
Q8For the following options, what is the most satisfactory one for the current use of this option? & 1.000 & .417 \\
Q9 Which type of WeChat apple program do you use the most to help your academic life? & .523 \\
Q10 Do you think that the application rate of WeChat applets for education and teaching is high at & 1.000 & .50 \\
this stage? & 1.000 & .505 \\
Q11 If you add a small program about education and teaching, what is your opinion? & 1.000 & .588 \\
Q12 If your school has its own WeChat applet, you can check the results, report the class, accept th & 1.000 & .532 \\
notice, recharge, etc. Your attitude towards this is. & 1.000 & .789 \\
Q13 What type of program do you most want to add to the WeChat applet: & 1.000 & .772 \\
Q14 Select a score for the "Logistics Service" module & 1.000 & .823 \\
Q15 Select a score for the "Teaching Service" module & 1.000 & .807 \\
Q16 Select a score for the "Medical Health" module & 1.000 & .680 \\
Q17 Select the score for the "Principal Mailbox" module & 1.000 & .707 \\
Q18 Select the score for the "Online Payment" module & 1.000 & .687 \\
Q19 Select the score for the "Campus Card Service" module & \\
Q20 Select a score for the "Student Financial Inquiry" module &
\end{tabular}

Table 5. Total variance of interpretation

\begin{tabular}{lrrrrrr}
\hline \multirow{2}{*}{ Ingredients } & \multicolumn{3}{c}{ Exitial eigenvalue } & \multicolumn{3}{c}{ Extract square sum loading } \\
\cline { 2 - 7 } & Total & \% of variance & Cumulative \% & Total & \% of variance & Cumulative \% \\
\hline 1 & 4.914 & 24.570 & 24.570 & 4.914 & 24.570 & 24.570 \\
2 & 1.870 & 9.351 & 33.921 & 1.870 & 9.351 & 33.921 \\
3 & 1.364 & 6.822 & 40.743 & 1.364 & 6.822 & 40.743 \\
4 & 1.211 & 6.056 & 46.800 & 1.211 & 6.056 & 46.800 \\
5 & 1.199 & 5.996 & 52.796 & 1.199 & 5.996 & 52.796 \\
6 & 1.083 & 5.417 & 58.213 & 1.083 & 5.417 & 58.213 \\
7 & .973 & 4.864 & 63.077 & & & \\
8 & .912 & 4.562 & 67.639 & & & \\
9 & .892 & 4.460 & 72.099 & & & \\
10 & .863 & 4.317 & 76.416 & & & \\
11 & .822 & 4.111 & 80.527 & & & \\
12 & .805 & 4.023 & 84.550 & & & \\
13 & .732 & 3.658 & 88.208 & & & \\
14 & .602 & 3.008 & 91.216 & & & \\
15 & .552 & 2.759 & 93.975 & & & \\
16 & .373 & 1.867 & 95.842 & & & \\
17 & .269 & 1.344 & 97.185 & & & \\
18 & .224 & 1.119 & 98.305 & & & \\
19 & .178 & .888 & 99.193 & & \\
20 & .161 & .807 & 100.000 & & & \\
\hline
\end{tabular}

Extraction method: principal component analysis. 
The researchers focus on the fifth and sixth questions, which have a good correlation (Table 4, Table 5). At the same time, these two questions are valuable for the researchers' research. The data from the above table is combined with the questionnaire to classify the statistics. Sorting out the questionnaires of Sino-foreign cooperative education students (The question is valid for the number of times: 177). The results are as follows: Type of screening: Sino-Foreign Undergraduate Cooperative Education students + Q5What do you think is the most important thing you need to improve in your studies? + Q6 Which of the following functions do you think the current WeChat public account should add? (emergency)

Table 6. Q1 Your profession?

\begin{tabular}{lcc}
\hline \multicolumn{1}{c}{ Options } & Subtotal & Proportion \\
Philosophy, literature, history & 29 & $16.38 \%$ \\
Economics, management & 110 & $62.15 \%$ \\
Law, military science & 11 & $6.21 \%$ \\
Education, medicine, agronomy & 7 & $3.95 \%$ \\
Science, engineering & 11 & $6.21 \%$ \\
Art, sports & 9 & $5.08 \%$ \\
This question is valid for the number of times & 177 & \\
\hline
\end{tabular}

Table 7. Q2 What is your current type of schooling?

\begin{tabular}{lcc}
\hline \multicolumn{1}{c}{ Options } & Subtotal & Proportion \\
Traditional domestic university undergraduate education & 0 & $0 \%$ \\
Sino-foreign cooperative education, international school undergraduate education & 177 & $100 \%$ \\
Foreign undergraduate education & 0 & $0 \%$ \\
This question is valid for the number of times & 177 & \\
\hline
\end{tabular}

Table 8. Q5 What do you think is the most important thing you need to improve in your studies?

\begin{tabular}{lcc}
\hline \multicolumn{1}{c}{ Options } & Subtotal & Proportion \\
Post-test summary, reflection & 38 & $21.47 \%$ \\
Organize notes & 40 & $22.6 \%$ \\
Foreign language level & 48 & $27.12 \%$ \\
Personal development direction and future career planning & 51 & $28.81 \%$ \\
This question is valid for the number of times & 177 & \\
\hline
\end{tabular}

Table 9. Q6 Which of the following functions do you think the current WeChat public account should add?

\begin{tabular}{lcc}
\hline \multicolumn{1}{c}{ Option } & Subtotal & Proportion \\
Professional course webcast recording course & 42 & $23.73 \%$ \\
Exam registration & 42 & $23.73 \%$ \\
Appointment classroom, course guidance & 39 & $22.03 \%$ \\
Internship or job recommendation & 54 & $30.51 \%$ \\
This question is valid for the number of times & 177 & \\
\hline
\end{tabular}

Students major in Economics, management and Philosophy, literature, history accounts for a large proportion, especially Economics, management (Table 6) and their schooling types (Table 7). Personal development direction and future career planning accounts for the largest proportion of Q5 (Table 8). Internship or work unit recommendation take up the largest percentage of Q6 (Table 9).

\section{CONCLUSION}

With the rise of Sino-foreign cooperative undergraduate education in recent years, the number of the student is gradually increasing. The research is meaningful to the WeChat platform optimization of Sino-foreign cooperative education and also helpful for understanding students' needs of different educational forms. Based on the above data, the researchers find that the WeChat public platform should promote the following points in the professional courses of Sino-foreign cooperative undergraduate students: (1) Focus on improvement of 
Personal development direction and future career planning accounts, and combined with professional courses knowledge. (2) Add and optimize Internship or job recommendation function. (3) The improvement of the above suggested functions should focus on the students who study Economics, management, Philosophy, literature and history professional courses.

Due to WeChat instant communication and resource sharing, it broke the time and space limitations and changed the teaching mode of traditional classrooms to make communication more convenient (Zeng et al., 2016). So researchers believe that with the gradual improvement of WeChat function, it will further enhance its quality in education. In addition, it will be more conducive to different types of students to get the information they want through the WeChat platform.

\section{REFERENCES}

China Internet Network Information Center. (2019). Statistic Report on the Development of China's Internet, China Internet Network Information Center, available at: http://www.cnnic.net.cn/hlwfzyj/hlwxzbg/hlwtjbg/201902/ P0201903185 23029756345.pdf, [Accessed: May 20th, 2019].

Kim, J., \& Mueller, C. (1978). Factor analysis. Beverly Hills, Calif.: Sage.

Mobile Inverted Constructivism: Education of Interaction Technology in Social Media. (2016). EURASIA Journal of Mathematics, Science \& Technology Education, 12(7).

Shi, Z., Luo, G., \& He, L. (2017). Mobile-assisted Language Learning Using WeChat Instant Messaging. International Journal of Emerging Technologies in Learning (Ijet), 12(02), 16. doi: 10.3991/ijet. v12i02.6681.

Yu, Q.C., \& Tang, S.H. (2019). Mobile Internet Blue Book - Annual Report of China Mobile Internet Development Report 2018, Institute of People Net, Beijing, China.

Zeng, F., Deng, G., Wang, Z., \& Liu, L. (2016). WebChat: a new clinical teaching tool for problem-based learning. International Journal of Medical Education, 7, 119-121. doi: 10.5116/ijme. 5708.e5c4.

Zhang Y.C., \& Wu H.Y. (2013). "Mobile Micro-learning: The New Generation Employees' New Mode of Continuing Education_A case study on WeChat Public Platform." Modern Educational Technology, Vol. 23, No.11, pp 79-84. 